\title{
INTERNACIONALIZAÇÃO EM INGLÊS: SOBRE ESSE TAL DE UNSTOPPABLE TRAIN E DE COMO ABORDAR A SUA LOCOMOTIVA $^{1}$
}

\author{
Internacionalización en inglés: acerca de este Unstoppable Train y como tratar su \\ locomotora.
}

\author{
Clarissa Menezes Jordão ${ }^{2}$ Eduardo Henrique Diniz de Figueiredo ${ }^{3}$ Gabriela Fagundes Laufer ${ }^{4}$ \\ Thaina Caroline Frankiw ${ }^{5}$
}

Recibido 28/12/2019

Aceptado 28/01/2020

\section{RESUMO}

Este texto apresenta uma pesquisa sobre internacionalização do ensino superior, desenvolvida em instituição pública no Brasil. A partir de uma problematização sobre as posições da língua inglesa no processo de internacionalização, situamos nosso locus de enunciação em perspectivas decoloniais, do Sul Global. Desse espaço, questionamos o que vemos como uma "febre" pelo EMI - English as a Medium of Instruction, na qual ministrar aulas em inglês parece ser o elemento central que define o grau de internacionalização de uma universidade. Apresentamos nossa posição de que a internacionalização é um processo que será realmente produtivo quando for definido a partir da importância do estabelecimento de relações entre onto-epistemologias no processo de formação de pesquisadores. Nesse sentido, defendemos políticas linguísticas que tomem a diversidade das diferentes áreas do saber como positivas e, portanto, se construam em torno da importância de que os processos de internacionalização não privilegiem uma língua em detrimento de outras.

Palavras-chave: internacionalização, ensino superior, inglês, EMI, Brasil

\section{RESUMEN}

Este texto presenta una investigación sobre internacionalización de la educación superior, desarrollada en una institución pública en Brasil. A partir de una problematización sobre las posiciones del idioma inglés en el proceso de internacionalización, situamos nuestro lugar de enunciación en las perspectivas de coloniales del Sur Global. Desde este espacio cuestionamos lo que vemos como una "fiebre" por EMI, donde enseñar inglés parece ser el elemento central que define el grado de internacionalización de una universidad. Presentamos nuestra posición de que la internacionalización es un proceso que será realmente productivo cuando se define a partir de la importancia de establecer relaciones entre las epistemologías en el proceso de capacitación de investigadores. En este sentido, abogamos por políticas lingüísticas que consideren positiva la diversidad de las diferentes áreas del conocimiento y, por lo tanto, se basen en la importancia de que los procesos de internacionalización no privilegien un idioma sobre otros.

Palabras clave: internacionalización - educación superior - inglés - EMI, Brasil

\section{ABSTRACT}

This text presents a research developed in a Brazilian public institution on the general topic of internalization of higher education. Starting from a problematization of the positions given to the English language in processes of internationalization, we situate our locus of enunciation on decolonial perspectives in the Global South. Grounded on such locus, we question what we see as a "fever" for EMI - English as a Medium of Instruction, in

\footnotetext{
${ }^{1}$ Os autores gostariam de agradeceràs pesquisadoras e aos pesquisadores Thais Cons, John Fiorese, Mateus Massaro, Bryan Pissinini, Alan Emmerich, Ariane Nascimento e AleksandraPiasecka-Till, por suas contribuições em diferentes momentos do desenvolvimento dessa pesquisa.

${ }^{2}$ Universidade Federal do Paraná (UFPR) e Conselho Nacional de Pesquisa (CNPq), clarissamjordao@gmail.com

${ }^{3}$ Universidade Federal do Paraná (UFPR), eduardo.diniz@ ufpr.br

${ }^{4}$ Universidade Federal do Paraná (UFPR), gabbielaufer@ gmail.com

${ }^{5}$ Universidade Federal do Paraná (UFPR), thaf4300@gmail.com
} 
which teaching in English seems to be the central key defining the degree of internationalization in a university. Our position is that, in order to be productive, the process of internationalization needs to be understood from a realization of the importance of establishing relationships among different onto-epistemologies, especially regarding how researchers are educated, trained or formed in higher education. For that matter, we make the case for language policies that take positively the diversity of different areas of knowledge, and therefore inform processes of internationalization that do not privilege one language to the detriment of others.

Keywords: internationalization, higher education, English, EMI, Brazil

The neoliberal transnationalization of the university and the parallel conversion of higher education into a commodity are creating a highly segmented and unequal global university system. SOUSA SANTOS, 2018, p. 271

\section{Introdução}

Os processos de internacionalização do ensino superior no Brasil, em especial nas universidades públicas, têm recebido cada vez mais atenção na cena nacional nos últimos anos. A interconectividade e a rapidez da comunicação da era web 2.0 facilita comparações constantes entre as práticas e produtos de instituições acadêmicas por todo o planeta, acelerando a competitividade e a produtividade do ensino e da pesquisa universitárias mundo afora. Assim sendo, a mobilidade acadêmica se acentua, também, através do contato intensificado entre instituições e do desejo de internacionalizar, desejo esse movido pela consciência da importância das trocas e da cooperação na construção de conhecimento científico, da mesma forma que pela concorrência entre as instituições e pela busca por lucratividade nos casos em que a educação superior se comodificou e tornou fonte de rendimentos (Chowdhury e Le Ha, 2014).

Neste panorama, tem sido cada vez mais comum nos depararmos com notícias sobre a classificação de universidades e índices de qualidade que destacam o "grau" de internacionalização de cada instituição classificada (RUF - Ranking Universitário Folha"; Times Higher Education - World University Rankings ${ }^{7}$ ). Tais rankings trabalham com indicativos globais, buscando identificar características comuns a universidades no mundo todo, e assim partem do pressuposto de que existiria -ou se deveria buscar- algo que permitisse a comparação entre instituições distribuídas por todo o planeta. Essa suposição parece encontrar-se embasada nos ideais da modernidade, ligados ao desejo de controle que se materializa na construção de uma homogeneidade a ser alcançada, mesmo que a altos custos.

Juntamente com a modernidade vem a globalização, em sua vertente universalizante e hierarquizadora, e, consequentemente, a projeção de uma lingua franca que permita a comunicabilidade e as trocas entre instituições diferentes que se materializam em diversas culturas acadêmicas, epistemológicas, ontológicas e linguísticas bastante diferentes entre si (Sousa Santos, 2007).

Nesse panorama, mentalidades geradas pela modernidade/colonialidade encontram dificuldades de lidar com tamanha pluralidade, e buscam formas de domar a complexidade das trocas que se instauram na diferença. Essa busca pode, por vezes, significar o necessário (para um suposto "bem coletivo") silenciamento daquilo que se apresenta diferente; pode significar o posicionamento inferior daquilo que se entende como destoante na escala de "qualidade universal"; pode significar o apagamento ou ostracismo daquilo que se caracteriza

${ }^{6}$ https://ruf.folha.uol.com.br/2018/o-ruf/ranking-universidades/

${ }^{7} \mathrm{ttps}$ ://www.timeshighereducation.com/student/best-universities/most-international-universities-world 
pela diferença em relação ao padrão. $\mathrm{O}$ estabelecimento de um padrão, portanto, tem o imenso risco de invisibilizar práticas locais ou colocá-las na sombra quando esse tipo de classificação de instituições alcança reconhecimento internacional. Em outras palavras, na busca por posições bem colocadas nos rankings, muitas práticas educativas e de pesquisa com características locais perdem sua importância diante do padrão global, muitas vezes sem a percepção de que tal padrão nada mais é do que um desejo local projetado como global (Mignolo, 2000; Silvestre, 2016).

Como afirma Martinez (2017), linguagem e identidade existem em meio a diferenças e conflitos de várias ordens, transpassadas que são, dialogicamente, por questões de caráter histórico, social e político. Partindo deste entendimento, pode-se dizer que o discurso da internacionalização nos cursos superiores é uma "construção ideológica" (ibidem, p. 16). Assim como a globalização, a internacionalização surge como um fenômeno em que todos os participantes são caracterizados como encontrando-se aparentemente em posições iguais, ou seja, tendo os mesmos direitos e deveres. Contudo, sabe-se que esta perspectiva é bastante questionável, pois o processo parece estar fazendo do ensino superior um espaço onde só aumenta a distância entre pobres e ricos, perpetuando relações desiguais de poder. Nas palavras de Martinez (2017, p. 18):

As sociedades ocidentais, ou as chamadas democracias, vivem, aparentemente, um contexto de trocas e de simetrias, não apenas economicamente, mas também cultural e socialmente. Nesse sentido, torna-se natural aceitar a perspectiva de que estão todos inclusos igualitariamente e que o inglês ocupe a posição privilegiada de língua global. Essa forma de entender a vida em sociedade, entretanto, esconde sua própria genealogia, esconde a história da globalização anterior à atualidade, desde a colonização, na qual trocas sempre foram de mão-única e relações de poder estavam longe de serem simétricas, sendo, pelo contrário, sempre hierárquicas. Na globalização hegemônica sofre-se, assim, do mal de achar que todos os valores são iguais, de que todos os saberes têm o mesmo valor, de que todas as culturas são simétricas, pois essa globalização hegemônica esconde a colonialidade.

Tal colonialidade inferioriza, por exemplo, as epistemologias locais em prol de uma suposta superioridade dos modos de construir ciência do Norte Global (Pennycook e Makoni, 2020), fazendo com que via de regra, nos processos de internacionalização no Sul Global, as estruturas acadêmicas emulem aquelas das universidades mais bem ranqueadas nos índices internacionais. Desse modo, o processo se apresenta bem distante de relações igualitárias de troca, de compartilhamento, de colaboração: ao invés da busca em direção a uma horizontalização maior das práticas universitárias, ao invés do contato colaborativo interinstitucional, ao invés do desejo pelo encontro com a diferença, os processos de internacionalização parecem almejar, em geral, a uniformização das práticas de construção de conhecimento, assim como de ensino-aprendizagem, ou seja, desejam a homogeneização das onto-epistemologias no ensino superior. Essa uniformização precisa apagar as práticas locais em detrimento daquelas desenvolvidas por instituições que estão em posições superiores nos rankings, mesmo que se perceba tais rankings como parciais, relativos, contingenciais.

Diferentemente desses desejos de apagamento, nosso grupo de pesquisadores entende os processos de internacionalização como produtivos apenas na medida em que sejam orientados pela busca por estabelecer relações interativas com a diferença, ou seja, movidos pelo desejo de colaboração mútua, em processo de mão dupla. Isso significa pensar que o contato entre instituições, docentes, discentes, práticas de ensino-aprendizagem, 
procedimentos de construção de conhecimento científico produzirá onto-epistemologias distintas daquelas que existiam previamente ao contato, em todos os espaços envolvidos no processo, e não apenas na instituição que estiver mais abaixo em determinado ranking. Internacionalização para nós, como afirmou Martinez (2017), perpassa, portanto, o encontro com o outro. Como explicado pela autora, não pode haver práticas de internacionalização sem que se pense em encontros, relações, conflitos e convívio com o outro, em uma relação intercultural.

A conclusão desta introdução pode ser óbvia: globalização, modernidade e internacionalização estão conectadas num emaranhado de possibilidades produtivas e restritivas, conforme forem guiadas por um desejo institucional mais comercial ou mais formativo. Nesse emaranhado de desejos, a internacionalização das universidades parece atrair um produto cultural conhecido como inglês como língua franca, ou seja, uma construção da língua inglesa como meio de comunicação internacional. O discurso dominante reforça o inglês como língua global do conhecimento acadêmico e das publicações científicas, e as universidades no mundo todo têm disputado quem oferta mais disciplinas em inglês e assim consegue atrair mais estudantes internacionais (Gimenez, 2016), aumentando seu lucro financeiro e/ou ampliando possibilidades de cooperação internacional.

É sobre as relações entre a língua inglesa como meio de instrução (EMI) e os processos de internacionalização de universidades brasileiras que dedicaremos nossa atenção na próxima seção, pano de fundo para a análise dos dados construídos na pesquisa que originou o presente texto. À guisa de preparação dos leitores, informamos desde já que a seção principal deste texto, "Língua inglesa e internacionalização", apresentará trechos das entrevistas realizadas com os participantes da pesquisa de campo que fizemos nos últimos dois anos, entretecidos às nossas reflexões resultantes das leituras que realizamos durante o mesmo período. Escolhemos estruturar assim nosso texto para tornar a leitura menos repetitiva e mais adequada a nossos pressupostos epistemológicos, uma vez que consideramos os saberes construídos pelos participantes como tão importantes quanto aqueles publicados em textos acadêmicos especializados. Nesse sentido, ao citar falas diretas dos participantes, usaremos os apelidos que eles próprios se deram ao preencher os termos de consentimento livre e esclarecido.

\section{A Pesquisa}

A partir do cenário delineado nas seções anteriores, o que se segue aqui busca analisar os processos da internacionalização em uma universidade pública brasileira. Nosso foco de análise está em questões de linguagem como o EMI, a interculturalidade, a decolonialidade e o papel da língua inglesa no ensino superior. Para isso, tomamos como partida os resultados das pesquisas desenvolvidas por nós no âmbito do Programa Institucional de Bolsas de Iniciação Científica (PIBIC) intituladas Multiletramentos, Internacionalização e Língua Inglesa no Brasil: "em se plantando, tudo dá”? e Conceitualizações do Inglês como Língua Global. O primeiro objetivo da nossa equipe de pesquisa era entender como as ações de internacionalização estavam se desenvolvendo nos programas de pós-graduação de uma universidade pública federal do Brasil e quais as perspectivas que docentes e discentes tinham sobre este assunto. Ao alcançar este primeiro objetivo, desenvolvemos então a segunda etapa da pesquisa, com a realização de entrevistas presenciais de cunho etnográfico.

Na primeira etapa, realizada nos anos de 2016 a 2018, o grupo criou um questionário de sondagem que foi enviado a diversos docentes e discentes de pós-graduação da instituição participante. As questões estavam divididas em 3 partes: concepções de internacionalização, práticas em que os participantes se inseriam e uso de línguas estrangeiras nas atividades de 
pesquisa e na vida cotidiana, com perguntas tanto de múltipla-escolha quanto dissertativas. $\mathrm{O}$ intuito do questionário era descobrir as perspectivas dessas pessoas sobre a presença ou ausência da língua inglesa nos processos de internacionalização, bem como suas percepções sobre níveis de proficiência, planejamento institucional e experiências com a internacionalização em geral. Ao todo foram obtidas respostas de 123 docentes e 283 discentes. Os dados gerados nesta etapa foram muito ricos e com eles foi possível delinear um esboço de como a internacionalização estava se dando na universidade em questão. Nessa etapa surgiram temas importantes, como a falta de diretrizes institucionais concretas sobre como e para quê internacionalizar, que nos fizeram pensar no panorama nacional como um todo (dados quantitativos obtidos nessa fase da pesquisa, bem como sua análise e resultados, serão publicados em outro artigo, atualmente em estágio de desenvolvimento).

Especialmente os dados qualitativos gerados nessa etapa nos levaram a estruturar a segunda etapa da pesquisa, nos anos de 2018 e 2019, que consistiu em entrevistas presenciais com participantes voluntários - enviamos um convite por e-mail para participantes da etapa anterior, acrescidos de outros indicados por contatos pessoais nossos. Neste e-mail, apresentamos um resumo dos resultados obtidos na primeira etapa e informamos sobre os objetivos da segunda etapa, bem como sobre o formato e tempo previsto para a duração das entrevistas. Em resposta a esse convite, agendamos horário e local convenientes para os encontros com cada um dos 19 voluntários (10 discentes e 9 docentes). Tivemos uma mistura entre participantes novos e participantes que haviam respondido o questionário na etapa anterior, compondo um universo de pesquisadores envolvidos em diversas áreas do conhecimento, como por exemplo Ciências Exatas e da Terra, Ciências Biológicas, Engenharias, Ciências da Saúde, Ciências Agrárias, Ciências Sociais Aplicadas, Educação e Ciências Humanas.

O roteiro das entrevistas foi criado a partir dos aspectos que consideramos de maior interesse na nossa análise dos dados gerados com o questionário de sondagem. Decidimos que as entrevistas seriam semiestruturadas, e construímos um roteiro com nove itens: 4 sobre internacionalização em geral e 5 sobre a língua inglesa especificamente. Estas últimas se mostraram de extrema relevância, uma vez que a análise inicial do questionário de sondagem tinha nos mostrado que os participantes insistiam bastante sobre a importância da língua inglesa no processo de internacionalização.

Quanto à seleção dos participantes, convidamos docentes e discentes de diferentes áreas da pós-graduação, e os selecionamos com base na compatibilidade de agendas para a realização das entrevistas. Ao todo, como apresentado anteriormente, tivemos a participação de 10 discentes e 9 docentes. As entrevistas foram realizadas presencialmente ou por chamada de voz/vídeo. Acreditamos que o número de participantes dispostos a realizar as entrevistas tenha sido extremamente positivo, uma vez que eles costumam ser pessoas bastante ocupadas com suas atividades profissionais: o fato de terem se disposto, voluntária e anonimamente, a cederem a nossa pesquisa cerca de uma hora de suas vidas foi para nós evidência de que o assunto ocupa espaço importante em suas carreiras/trajetórias.

Nossas análises, apresentadas na próxima seção, foram produzidas em inúmeras leituras coletivas das transcrições das entrevistas, em encontros semanais nos quais compartilhávamos nossas interpretações e realizávamos mais estudos para ampliar nosso repertório teórico.

\section{Língua inglesa e internacionalização}

Considerando que o termo internacionalização tem se popularizado apenas recentemente, ainda não parece claro que exista um entendimento consensual sobre o que está 
envolvido nesse processo. No entanto, um pressuposto recorrente dentre os participantes de nossa pesquisa, nas suas duas fases, chamou muito a atenção: a ampla maioria destacou a ideia de que o inglês seria "a língua da ciência, se publicarmos em português nossa pesquisa não terá um bom alcance" (Alice, docente). Outros modos de expressar essa ideia são, por exemplo, o que nos disseram Ana e Louis (discentes) respectivamente:

“...pra mim é o inglês dentro e fora da universidade. Eu falo francês, eu fiz um pós-doutorado na França, fiquei um ano e meio lá, mas dentro do laboratório eu falava inglês. E hoje quando eu falo com eles, o que é recorrente porque a gente continua a colaboração, parceria, eu falo em inglês com eles porque pra mim é muito mais fácil discutir ciência, enfim, em inglês do que em francês. Eu não sei te dizer por que isso... - Ana

Nós temos alguns artigos em português, eu também já publiquei alguma coisa, mas as grandes conferências, as grandes revistas elas são em inglês. Não adianta querer achar "ah esse cara publicou aqui" mas aí cê vai ver e o cara não tem nenhuma citação, o trabalho dele é como se não existisse. Por que? Porque não gerou relevância. -Louis

Assim, vemos como a "relevância", o destaque, o dar-se a conhecer, enfim, o existir no mundo científico está relacionado à língua inglesa na visão não apenas destes, mas de muitos outros pesquisadores.

Também conhecido como Englishization (Kirkpatrick, 2011), o processo de utilizar a língua inglesa como meio de instrução (EMI) no ensino superior em universidades pelo mundo todo tem sido amplamente discutido e pesquisado (Macaro, 2015). Uma pesquisa rápida no Google Scholar permite acessar um volume imenso de publicações com esse tema: numa busca realizada em junho de 2019 , por exemplo, pela expressão "english as a médium of instruction" foram encontrados 1.180 .000 textos em inglês, 140.000 em português.

No entanto, o uso institucional de EMI tem sido criticado por via de regra favorecer um pequeno número de alunos, ou seja, aqueles com proficiência em língua inglesa. Embora sentir-se confiante no uso da língua inglesa possa facilitar o intercâmbio de docentes e discentes, a oferta de disciplinas em inglês em países em que essa língua não é a língua de comunicação pode excluir do processo educativo uma boa parcela da população, que é o que se observa especialmente no caso do Brasil, onde a educação básica pública tem sido criticada por não preparar os alunos para o contato internacional (Thiesen, 2017). Nesse sentido, cabe ainda ressaltar que o uso de EMI não se restringe ao uso mecânico de um ou outro código linguístico apenas, mas envolve -como no caso de qualquer outra línguaquestões onto epistemológicas fundamentais para o processo de ensino-aprendizagem e este, por sua vez, envolve sempre o relacionamento das pessoas entre si e com o mundo. Não existe neutralidade nem transparência no uso de uma língua ou outra: trata-se de processos de construção, atribuição, interpretação, desenvolvimento de sentidos que se dão política, social e culturalmente, uma vez que o linguístico é sempre materializado na enunciação, ou seja, no espaço social (ideológico) de interação (Volochinóv, 2017). Como afirma Le Duk Mahn (2012, p. 224) sobre o ocorrido na Índia com o uso de EMI,

A desigualdade social é outro aspecto do EMI que traz preocupação. O caso da Índia é um exemplo. Lá, acredita-se que o EMI é vantajoso para alunos vindos de famílias mais favorecidas que usam o inglês há uma geração ou mais, mas coloca 
em desvantagem os outros alunos que não tem acesso a fontes de conhecimento em inglês ${ }^{8}$.

A dominação quase que absoluta exercida pela língua inglesa no contexto global de internacionalização da educação evidencia a perspectiva de que as línguas "têm sido usadas como instrumento de dominação, conquista e colonização através da história" (Garcia, 2019, p.152) $)^{9}$. Segundo Garcia (idem, ibidem), tal uso das línguas se faz possível a partir de uma determinada concepção de língua e sua ação sobre o mundo: para a pesquisadora, "se língua não fosse vista como um todo autônomo, onde um todo pode ser acrescentado a outro todo, mas como um sistema de práticas de linguagem complexas e dinâmicas no qual as pessoas se engajam para fazer sentido, então as assim chamadas línguas, como as conhecemos hoje, perderiam seu poder"10.

Os participantes de nossa pesquisa também não se mostraram alheios aos efeitos discriminatórios e excludentes que a promoção inquestionável do inglês à língua principal ou de maior alcance na internacionalização pode causar. A docente Daniele, por exemplo, destacou que

...há uma, um movimento forte de [...] da língua inglesa, pode e deve ser questionado, né, o fato de a gente ter grandes congressos de várias áreas, né, adotando uma única língua como seu referencial me preocupa bastante, né, porque daí só as pessoas que tiveram acesso e que dominam essa língua poder trocar, inclusive, conhecimentos, ou seja, eu só vou conhecer aquilo que as pessoas que falam inglês produzem, né, pessoas que falam outras línguas vão deixar de conhecer.

No entanto, a voz de Daniele parece estar isolada: para nossos participantes, e pesquisadores em geral, o inglês parece ser incontestavelmente " $A$ " língua da internacionalização do ensino superior (Macaro, 2015): raras vezes tal situação é problematizada, questionada ou sequer desafiada, embora pesquisas como a de Bührer e a nossa -em sua primeira fase- evidenciem resistência individual de docentes e discentes que, como Daniele acima, clamam por políticas plurilíngues para a internacionalização -uma discussão sobre as contradições desse discurso é apresentada em artigo atualmente sendo desenvolvido por nosso grupo de pesquisa-. Além dessa concreta violência simbólica (Bourdieu, 1996) exercida pela projeção do inglês como algo inevitável em processos de internacionalização, raríssimos são os estudos na área de linguística aplicada que se debruçam sobre as especificidades do papel do inglês como lingua franca em contraste com o uso de inglês em seu papel de língua materna (Jenkins, 2019). Tratam-se aqui de funções da língua diferenciadas, que estabelecem também usos diferenciados (Diniz de Figueiredo, 2018) em contextos diferenciados -ou as semblages, como diriam Pennycook, 2018 e Latour, 2005-. Ensinar língua inglesa em/para contextos de internacionalização, aponta Diniz de Figueiredo (2018, p.126),

\footnotetext{
${ }^{8}$ No original: "social inequality is another aspect of concern with EMI. The case of India is an example. There, EMI is believed to be advantageous for students from wealthy families which have used English for a generation or more, but disadvantageous for other students who do not have access to knowledge resources in English."

${ }^{9}$ No original: "language has been used as a tool of domination, conquest and colonization throughout history."

${ }^{10}$ No original: "if language was seen not as an autonomous whole, where one whole can be added to another whole, but as a system of complex and dynamic language practices in which speakers engage to make meaning, then named languages, as we know them today, would lose their power."
} 
...é fazer com que o aluno aprenda a usá-la em diferentes contextos comunicativos, com diferentes falantes de diferentes lugares, entendendo que terá que negociar sentidos com eles, que haverá diferenças entre seu nível de proficiência e os níveis dos seus interlocutores, que haverá incertezas em como ele irá se comunicar com essas pessoas, que ele terá que usar estratégias comunicativas para isso, que terá que ser inteligível [.. ]. Ou seja, não se ensina língua franca. A língua franca é uma função do inglês e uma atitude com relação a seu uso.

Desse modo, a língua inglesa da internacionalização seria uma língua predominantemente voltada para o contato intercultural, para a interlocução entre pessoas de culturas diversas; em se tratando de ensino superior, então teríamos que enfocar o contato entre culturas acadêmicas e onto epistemologias diversas, não apenas entre línguas diferentes ou entre supostas variantes de algo entendido como uma mesma língua. Assim, ao tratar de EMI ou de qualquer uso do inglês em ambientes de internacionalização, estaríamos necessariamente tratando de trocas, interrelações, contatos. Numa concepção bakhtiniana e pós-estruturalista de língua e meaning-making, tais trocas acontecem sempre em dialogia, ou seja, em relações imersas em questões de poder, diferença, conflito: refletidas e refratadas em cada situação de enunciação (Bakhtin, 2017; Voloshinóv, 2017).

É a partir dessa concepção de língua e de inglês em contextos de internacionalização do ensino superior que partimos para a construção de nossos entendimentos sobre o papel da língua inglesa nos processos de internacionalização das universidades brasileiras em geral. Esse é o lugar que nos leva a construir as interpretações que apresentamos aqui para os dados gerados com os agentes deste processo. Mas antes de prosseguirmos com nossas leituras sobre os dados gerados em nossa pesquisa, ainda precisamos fazer algumas observações sobre o uso de inglês em ambientes universitários no Brasil.

Kirkpatrick (2014, p.6) aponta algumas dificuldades que precisam ser consideradas em universidades de países onde o inglês é uma língua estrangeira, dentre elas o fato de que docentes e discentes podem ser forçados a usar "uma língua que não é sua primeira e na qual eles provavelmente não têm um nível de proficiência tão grande" ${ }^{11}$. Para o pesquisador, isso pode deixá-los em grande desvantagem, pois está comprovado que se aprende melhor quando se usa a língua materna - o autor cita o relatório da UNESCO já em 1953 e da Education Comission de Hong Kong em 2005 para referendar sua posição.

Além disso, outra questão destacada por Kirkpatrick está na necessidade de que as universidades reavaliem suas políticas linguísticas, compreendendo a existência e a legitimidade de novas variedades do inglês; reconhecer que pessoas multilíngues usam ILF de maneiras que podem diferir das normas de falantes nativos, o que não invalida o uso de ILF; que multilíngues, quando apropriado, precisam ter a permissão de usar suas habilidades ao longo do ensino e da aprendizagem; e que uma universidade que visa desenvolver programas e graduados bilíngues ajudaria a não somente promover outras línguas de educação e acesso a bolsas além do inglês, como também se provaria atrativa a pessoas que desejam operar com sucesso em um mundo multilíngue. (Kirkpatrick, 2014, p.13) ${ }^{12}$

\footnotetext{
${ }^{11}$ No original: "a language which is not their first and in which they are unlikely to have as great a level of proficiency"

${ }^{12}$ No original: "the existence and legitimacy of new varieties of English; recognizing that multilinguals use ELF in ways that may differ from native speaker norms, but that this does not invalidate ELF use; that multilinguals,
} 
Dentro dessa perspectiva, que chamaremos aqui de ELF, é indiscutível que questões de conscientização linguística e estratégias de comunicação tomam primazia sobre questões voltadas à adequação, correção ou acuidade gramatical (Jordão e Marques, 2018). Trata-se, portanto, de uma concepção de língua inglesa como elemento para interação entre pessoas e saberes, como espaço de construção de sentidos em dialogia, ou seja, um espaço no qual se instauram processos de negociação constante de sentidos elaborados de modo multimodal, socialmente, num embate permanente em meio à pluralidade de possibilidades de sentidos negociados constantemente e sempre imersos em relações de poder. Assim, a proficiência linguística só pode ser determinada de modo situado, conforme se estabeleçam e compreendam os contextos de enunciação específicos de cada situação de uso da língua; isso significa deslocar o construto idealizado do falante nativo como regra geral e abstrata para legitimidade da língua, privilegiando, ao invés disso, cada espaço de uso e cada situação, em sua contingencialidade, como determinante do grau de sucesso de um momento comunicativo.

Em nossa pesquisa, descrita na seção anterior, tomamos como ponto de partida para nossas leituras e interpretação dos dados essa concepção de língua e de proficiência em inglês - situada, contingente, relativa a cada contexto específico de comunicação. Entendemos também assim o processo de internacionalização do ensino superior como um todo, seguindo Hans de Wit (2013) ao destacarmos a importância de se pensar não apenas em como, mas também e principalmente em porquê internacionalizar. Para o pesquisador, em geral, as razões que motivam a internacionalização das universidades se dividem em fatores de ordem política, econômica, sociocultural e acadêmica, e são fatores estabelecidos localmente, conforme a conjuntura de cada instituição. Cabe, portanto, como afirmam De Wit et al (2013), a cada instituição avaliar os prós e contras do processo de internacionalização, bem como estabelecer os moldes nos quais ela se dará. Caberia também, consequentemente, pensarmos que cada instituição deveria estabelecer suas políticas linguísticas contextualmente, levando em conta a conjuntura em que se situa, sua inserção social, seu projeto educacional, suas possibilidades e desejos locais.

\section{A língua inglesa na universidade pública}

Apesar do que apontamos na seção anterior, a comunidade participante da pesquisa desenvolvida por nós na IES pública pareceu, via de regra, considerar como dada e imutável a primazia da língua inglesa neste cenário, como se fosse o unstoppabletrain (MACARO, 2015 , p.7). Para nós, a metáfora usada por Macaro permite várias leituras, dentre as quais a possibilidade de que esse trem em disparada esteja desgovernado, prestes a sair dos trilhos e causar danos irreparáveis.

Talvez até, parece-nos por vezes, já esteja causando grandes danos; mas talvez tais danos ainda possam ser revertidos em dimensões produtivas para reflexão e superação tanto da síndrome do Impostor quanto do colonialismo de nossas práticas. Ao analisarmos os comentários feitos pelos participantes de nossa pesquisa, especialmente nas entrevistas gravadas em áudio, percebemos que muitos participantes relataram desenvolverem constantemente práticas envolvendo leitura e escrita de artigos em língua inglesa, além de relacionarem-se com pesquisadores de outros países tendo a língua inglesa como espaço de

where appropriate, need to be allowed to use their multilingual skills in the course of teaching and learning; and that a university which aimed to develop bilingual programs and bilingual graduates would not only help promote languages other than English as languages of education and scholarship, but would also prove attractive to people who want to operate successfully in a multilingual world." 
comunicação. Entretanto, nos chamou a atenção a baixa autoestima destes participantes quanto ao uso da língua: ao mesmo tempo em que afirmavam desenvolverem práticas frequentes em língua inglesa, diziam-se não ter domínio suficiente da língua. Declarações como as da docente Annia ${ }^{13}$, que reproduzimos em seguida, foram frequentes:

Eu acho que hoje, na verdade quando eles chegam na graduação eles tiveram um contato maior com o inglês do que eu tive, por exemplo, quando eu cheguei na graduação. Até a questão de série, de filme, a gente não tinha, assistia filme dublado, né?

Docentes e discentes parecem constantemente insatisfeitos com sua proficiência linguística, partindo de uma concepção compartimentalizada de saberes em habilidades, referindo-se frequentemente às dificuldades com a oralidade, mesmo quando admitem proficiência na escrita. Foi por exemplo o que nos disse o discente Leo ao falar sobre seu inglês. Segundo ele, "no meu caso eu leio bem e escrevo também, mas na parte da comunicação oral ainda sofro um pouco". Leo, representando uma crença generalizada entre os participantes da pesquisa, acredita que quanto mais contato com a língua melhor é a proficiência. "Por isso", continua ele, "se houvessem mais palestras e eventos durante os cursos na [IES] os alunos poderiam praticar mais e desenvolver melhor a fala na língua inglesa". Sua confiança nisso chega ao ponto de ele afirmar, logo em seguida, que

É necessária a reestruturação dos programas de doutorado de forma que o inglês seja usado como primeira língua, a exemplo de programas como a EBAPE e o INSPER em administração, especialmente durante as aulas. Somente com o contato diário com o idioma é que realmente os discentes estarão aptos a comunicar-se uma vez que estiverem no exterior.

Como Leo, também a ampla maioria dos participantes defendeu a inclusão de disciplinas em EMI, bem como práticas acadêmicas em geral em língua inglesa, a fim de aumentar o contato de docentes e discentes com a língua. Não houve espontaneamente qualquer comentário sobre qual conhecimento de inglês seria necessário para que houvesse uma participação produtiva nessas práticas, nem sobre como lidar com situações em que alunos ou professores se sentissem desconfortáveis com o uso de inglês nas aulas, ou em que não se sentissem preparados para tal realidade. Ao contrário, pareceu haver um pressuposto de que seria obrigação de todos estarem prontos, mesmo que essa dimensão da prática acadêmica não fosse explicitada nos protocolos institucionais como uma demanda dos cursos.

Outro discente, Cássio, deixa esse pressuposto bastante claro. Para ele, assim como para a maioria dos participantes da pesquisa, se aprende fazendo - se aprende inglês usando a língua. Em suas palavras, “Eu acho que se aprende assim, né, praticando. Então eu acho que não é real a pessoa falar que não teve preparo, uma que para ela entrar no mestrado, ela já teria que ter um inglês, teria que ter uma noção de inglês”. No entanto, esse não é um inglês que se faz dentro da perspectiva translíngue, ou dentro do momento pós-normativo em que o inglês padrão é entendido como uma função relativa a determinados contextos (Widdowson, 2003), mas não necessariamente ao contexto da sala de aula que usa EMI, por exemplo. Como Cássio, também a maioria dos participantes da pesquisa acabou por evidenciar a ausência de preocupação com o caráter excludente que tais práticas em língua inglesa podem ter, conforme mencionamos na seção anterior: a colonialidade que observamos na aceitação

${ }^{13}$ Os nomes dos participantes foram modificados a fim de garantir seu anonimato. As escolhas por pseudônimos foram realizadas pelos pesquisadores. 
ou naturalização do inglês como a língua do acesso ao conhecimento acadêmico parece construir uma linha abissal (Souza Santos, 2018) que, em sua invisibilidade, silencia ou anula todos os que são colocados do outro lado da linha. Isso significa que a pouca preocupação com as implicações sociais e educativas de se adotar EMI e outras práticas em língua inglesa em uma universidade pública brasileira, assim como a pressuposição de que alunos e professores já deveriam saber inglês quando entram na universidade, desconsideram a realidade contextual da educação pública e isentam a instituição da responsabilidade por oportunizar que todos os alunos acompanhem as práticas instituídas na universidade. Nesse sentido, parece existir inclusive, em alguns casos, um certo preconceito em relação a usos de inglês que não se conformam às expectativas de um inglês padrão, como na fala da aluna Alice:

Acho que falta os professores falarem inglês e fazerem curso de inglês, porque eu conheci vários professores que nunca fizeram curso de inglês, aprenderam inglês, assim, na TV, no jogo, então eles têm um vocabulário que acaba sendo um pouco limitado pra entrar em contato com outras pessoas no meio acadêmico.

No entanto, Alice foi a única a verbalizar tal preconceito. Nas falas dos outros participantes ficou bastante evidente que o local de nascimento ou origem dos envolvidos em práticas com a língua inglesa seria irrelevante: para a maioria o importante é praticar, não interessa como, onde, nem com quem. Vários docentes e discentes, portanto, corroboraram essa posição, como fica claro na fala de Antônia, por exemplo:

$\mathrm{Na}$ verdade, eu acho que meu inglês ficou fluente mesmo quando eu fiquei na França. Porque daí eu usava o inglês o tempo todo pra discutir ciência, ficava o tempo todo falando inglês. E é isso que te dá fluência, porque senão você sabe mas às vezes falta palavra na hora de construir uma frase, construir um raciocínio... fica mais lento. Vivenciando o idioma no dia-a-dia, o tempo todo, que você pega.

\section{Considerações Finais}

Diante do unstoppabletrain da internacionalização em língua inglesa, é preciso qualificar a metáfora: trem em desabalada carreira não tem tempo para pensar, para considerar a paisagem, para planejar um bom aproveitamento de seu combustível, e tem grandes chances de descarrilar. Estamos pensando nesse trem de dentro de uma universidade, espaço cuja missão maior parece ser a de refletir, ponderar, analisar - e para isso é preciso tempo, e talvez uma velocidade mais baixa. Estamos pensando nesse trem de dentro de uma universidade que é pública, ou seja, que tem por missão tratar a todos como tendo os mesmos direitos, o que significa olhar para todos os alunos e professores da comunidade universitária como seres humanos inteligentes e capazes de ensinar e aprender (Ranciére,1991). Isso não significa, obviamente, tratar a todos da mesma maneira, mas sim a cada um de acordo com suas necessidades.

Essas necessidades envolvem dimensões complexas do processo de ensinoaprendizagem que se dá nas universidades. Diferentes áreas e tipos de conhecimento instituem diferentes práticas de construção de sentidos, assim como diferentes línguas também estão atreladas a diferentes práticas discursivas. Vimos, em nosso panorama pelas várias áreas de conhecimento na pesquisa parcialmente apresentada aqui, que docentes e discentes parecem não ter refletido muito sobre o papel da língua inglesa na internacionalização, a maioria deles tendo repetido motes do senso comum: "é preciso 
internacionalizar" -pouco se problematizam as motivações e consequências sociais e educacionais do processo-; "internacionalização só acontecerá se for maciçamente em língua inglesa"; "só teremos intercâmbios produtivos com países onde o inglês é o meio de instrução e/ou a língua materna"; "nossos alunos e colegas professores não sabem inglês".

As concepções de internacionalização e a pouca problematização da língua inglesa como meio de instrução, o famoso EMI, nas universidades brasileiras não parecem estar levando em consideração que as várias áreas do conhecimento, assim como os alunos e professores que a elas se ligam não são, nem deveriam ser, todos iguais, embora tenham os mesmos direitos. O que nos une nos processos de internacionalização é o interesse no estabelecimento de relações com os diferentes e com a diferença, não para perpetuar desigualdades ou reiterar hierarquias, mas para ampliar nossos repertórios de possibilidades. Fazer isso em apenas uma língua, a língua inglesa, é reduzir a um único universo o multiverso do conhecimento. Explicando melhor: a língua inglesa percebida enquanto língua internacional já vem carregada de multiplicidade, pois está cada vez mais desligada -ou "delinked", como pediu Mignolo, 2007- de nacionalidades específicas e entendida como língua franca de ampla circulação, adquirindo características locais (Guilherme e Menezes de Souza, 2019) conforme os contextos em que adquire existência. Mesmo assim, tal multiplicidade se torna unicidade quando o inglês é apresentado como se fosse a única alternativa, uma condição sinequa non para a internacionalização das universidades, "A língua" do acesso ao conhecimento produzido pela humanidade.

Esse raciocínio reduz outras línguas a um papel secundário, assim como o faz com conhecimentos, culturas e indivíduos associados a tais línguas. Ao estudarmos diferentes processos de internacionalização mundo afora, e ao conversarmos com os participantes da nossa pesquisa sobre EMI em nossas práxis, constatamos que o unstoppabletrain parece ternos atropelado: não problematizamos, não analisamos, não relacionamos, não refletimos, e com isso estamos marginalizando docentes e discentes, áreas de conhecimento, formas de saber que resistem ao inglês projetado como hegemônico. Especificamente sobre que inglês é esse a que todos se referem como sendo a língua universal da internacionalização, concluímos que tanto docentes quanto discentes parecem caracterizá-lo de forma instrumental, como se fosse a estrada de ferro que possibilita à locomotiva imprimir grande velocidade a carreiras bem-sucedidas no mundo globalizado. Dentro dessa visão, o ferro proveniente dos países tradicionalmente entendidos como os donos da língua, donos do conhecimento, mais evoluídos e com melhor infraestrutura, ou seja, os países do Norte Global geopolítico, seria um ferro de melhor qualidade, que permitiria às rodas da locomotiva deslizarem com mais fluidez. Tal deslizar se efetivaria, portanto, nas práticas de linguagem que atrelam aos construtos de falante nativo e inglês padrão as noções de proficiência e inteligibilidade, desconsiderando e apagando outros usos e outras práticas que não aquelas percebidas como características dos países centrais que seriam os "donos da língua".

Essa colonialidade, de acordo com Pessoa (2019, p. 106),

marca fortemente a educação linguística de várias formas, o que se constata pela importância da/o falante nativa/o das línguas que ensinamos, da norma padrão dessas línguas, dos livros didáticos produzidos nos Estados Unidos ou na Inglaterra, dos métodos de ensino desenvolvidos nesses dois países, do ensino de estruturas gramaticais, da abordagem trivial de temas em sala de aula etc. Marca igualmente a formação docente especialmente no que diz respeito à relação entre universidade e escola, pois a universidade é representada como o lugar onde se produz conhecimento, e a escola, como o lugar onde se aplica esse conhecimento. 
As discussões que apresentamos aqui podem talvez parecer uma vilanização do inglês, de seu uso na educação superior, e do EMI. É importante deixar claro que não é isso que estamos buscando fazer - até mesmo por sermos docentes e discentes da área de língua inglesa, e acreditarmos que o inglês seja uma língua importante na educação superior. $\mathrm{O}$ que buscamos mostrar com nossas reflexões é a necessidade de discutir, de forma crítica, a naturalização do inglês como "A" língua da internacionalização, bem como o próprio conceito de inglês (e de língua) que muitas vezes permeia discursos institucionais sobre internacionalização (incluindo os de docentes e discentes). Tal discussão implica em apreciações profundas sobre conceitos como língua, padrão, falante nativo, legitimidade, proficiência, entre tantos outros, além da conscientização sobre a natureza situada, relativa e translíngue (Canagarajah, 2013) das trocas interculturais. Acreditamos que esforços nessa direção podem trazer sentidos diferentes para entendimentos sobre o papel e status do inglês e sobre EMI.

Para nossa esperança, temos encontrado vozes na educação superior (inclusive no contexto universitário onde a presente pesquisa foi realizada) que têm buscado inserir o status do inglês na universidade em concepções plurilíngues, e que têm problematizado conceitos muitas vezes tomados como dados no trabalho com uso e ensino de línguas (tais como falante nativo, legitimidade e muitos outros, como citado anteriormente). Esperamos que o presente artigo seja uma contribuição para o aprofundamento dessa perspectiva crítica, que situa a língua inglesa dentro de um multiverso intercultural que se percebe produtivo diante da diversidade linguística nas práticas acadêmicas no ensino superior.

\section{Referências Bibliográficas}

Bakhtin, M. (2016). Os gêneros do discurso. São Paulo, Editora 34.

Bourdieu, P. (1996). A Economia das Trocas Linguísticas. São Paulo: EDUSP.

Chowdhury, R.\& Le Ha, P. (2014). Desiring TESOL and International Education: Market abuse and exploitation. Bristol: Multilingual Matters.

De Wit, H. (2013). Reconsidering the Concept of Internationalization.International Higher Education, (70), 6-7.

De Wit, H.et.al. An Introduction to Higher Education Internationalisation.Milan: Vita e Pensiero, 2013.

Diniz de Figueiredo, E. Afinal, de quem é essa língua? (2018). In C. Jordão et al (Eds.) Devaneios em Atas: distopias teóricas nos multiletramentos e inglês como língua franca. (pp 119-138). Campinas: Pontes.

Gimenez, T. English as a global language and the internationalization of universities. (2016). In N. ArturoSantos e M. L. Cárdenas (Eds). Investigaciones sin fronteras: new and enduring issues in foreign language education. Veracruz, México: Universidad Veracruzana.

Guilherme, M. e Menezes de Souza, L.M.T. (Eds.) (2019) Glocal Languages and Critical Intercultural Awareness: The South Answers Back. London: Routledge.

Jenkins, J. The internationalization of higher education: but what about its lingua franca? (2019) In Murata, K. (Ed.).English-medium Instruction from an English as a Lingua Franca perspective: Exploring the higher education context. London: Routledge.

Jordão, C. E Marques, A. English as a Lingua Franca and Critical Literacy in Teacher Education: Shaking Off Some "Good Old" Habits. In T. Gimenez, M. El Kadri, L. Cabrini e S. Calvo (Eds.).English as a Lingua Franca in Teacher Education: A Brazilian Perspective. De Gruyter: Hong Kong.

Kirkpatrick, A. (2011). Internationalization or Englishization: Medium of instruction in today's universities. Hong Kong: The Hong Kong Institute of Education.

Kirkpatrick, A. (2014). The Language(s) of HE: EMI and/or ELF and/or Multilingualism? The Asian Journal of Applied Linguistics, (1), 4-15.

Latour, B. (2005). Reassembling the Social: An Introduction to Actor-Network-Theory. Oxford: OUP.

Macaro, E. English Medium Instruction: Time to start asking some difficult questions. (2015). ModernEnglishTeacher, (24)2, 4-8.

Martinez, J. (2017). Entre Fios, Pistas E Rastros: Os Sentidos Emaranhados da Internacionalização da Educação Superior. (UnpublishedDoctoraldissertation) Universidade de São Paulo, São Paulo.

Mignolo, W. D.Delinking. (2007). Cultural Studies, (21)2, 449-514.

Pennycook, A. (2018). Post-humanist Applied Linguistics. London: Routledge. 
Pennycook, A. e Makoni, S. (2020). Innovations and Challenges in Applied Linguistic from the Global South. Routledge: Oxonand New York.

Pessoa, R. R. (2019). A Construção de uma Práxis Docente. (Unpublished Academic Memorial) Universidade Federal de Goiás, Goiânia.

Ranciére, J. (1991). The Ignorant Schoolmaster: five lessons in intellectual emancipation. Stanford: Stanford University Press

Silvestre, V. Práticas problematizadoras e de(s)coloniais na formação de professores/as de línguas: teorizações construídas em uma experiência com o Pibid. (Unpublished Doctoral dissertation) Universidade Federal de Goiânia, Goiás.

Sousa Santos, B. (2007). Beyond Abyssal Thinking: From Global Lines to Ecologies of Knowledges. Review, (30) $1,45-89$.

Souza Santos, B. de. (2018). O fim do império cognitivo. Coimbra: Almedina.

Thiesen, J., da S. (2017). Internacionalização dos Currículos na Educação Básica: concepções e contextos. ECurriculum, (15) 4, 991 - 1017.

Volochinóv, V. Marxismo e Filosofia da Linguagem: Problemas Fundamentais do Método Sociológico na Ciência da Linguagem. São Paulo: Editora 34.

Widdowson, H.G. (2003). Defining Issues in English Language Teaching.Oxford: OUP. 